\title{
Centrifugal telencephalic afferent connections to the main and accessory olfactory bulbs
}

\author{
Alicia Mohedano-Moriano ${ }^{1}$, Carlos de la Rosa-Prieto ${ }^{2}$, Daniel Saiz-Sanchez ${ }^{2}$, Isabel Ubeda-Bañon ${ }^{2}$, \\ Palma Pro-Sistiaga ${ }^{3}$, Miguel de Moya-Pinilla ${ }^{2}$ and Alino Martinez-Marcos ${ }^{2 *}$ \\ Facultad de Medicina de Albacete, Laboratorio de Neuroanatomía Humana, Departamento de Ciencias Médicas, Centro Regional de Investigaciones \\ Biomédicas, Universidad de Castilla-La Mancha, Albacete, Spain \\ 2 Facultad de Medicina de Ciudad Real, Laboratorio de Neuroplasticidad y Neurodegeneración, Departamento de Ciencias Médicas, Centro Regional de \\ Investigaciones Biomédicas, Universidad de Castilla-La Mancha, Ciudad Real, Spain \\ ${ }^{3}$ GIP Cyceron, Campus Jules Horowiz, Caen, France
}

\section{Edited by:}

Micheal Baum, Boston University, USA

\section{Reviewed by:}

Kevin R. Kelliher, University of Bridgeport, USA

Ningdong Kang, Washington

University in Saint Louis, USA

\section{*Correspondence:}

Alino Martinez-Marcos, Facultad de Medicina de Ciudad Real,

Universidad de Castilla-La Mancha,

Avda. de Moledores S/N,

13071 Ciudad Real, Spain.

e-mail: alino.martinez@uclm.es
Parallel to the olfactory system, most mammals possess an accessory olfactory or vomeronasal system. The olfactory and vomeronasal epithelia project to the main and accessory olfactory bulbs, which in turn project to adjacent areas of the telencephalon, respectively. New data indicate that projections arising from the main and accessory olfactory bulbs partially converge in the rostral telencephalon and are non-overlapping at caudal telencephalic levels. Therefore, the basal telencephalon should be reclassified in olfactory, vomeronasal, and mixed areas. On the other hand, it has been demonstrated that virtually all olfactory- and vomeronasal-recipient structures send reciprocal projections to the main and accessory olfactory bulbs, respectively. Further, non-chemosensory recipient structures also projects centrifugally to the olfactory bulbs. These feed-back projections appear to be essential modulating processing of chemosensory information. The present work aims at characterizing centrifugal projections to the main and accessory olfactory bulbs arising from olfactory, vomeronasal, mixed, and non-chemosensory recipient telencephalic areas. This issue has been addressed by using tracer injections in the rat and mouse brain. Tracer injections were delivered into the main and accessory olfactory bulbs as well as in olfactory, vomeronasal, mixed, and non-chemosensory recipient telencephalic structures. The results confirm that olfactory- and vomeronasal-recipient structures project to the main and accessory olfactory bulbs, respectively. Interestingly, olfactory (e.g., piriform cortex), vomeronasal (e.g., posteromedial cortical amygdala), mixed (e.g., the anterior medial amygdaloid nucleus), and non-chemosensory-recipient (e.g., the nucleus of the diagonal band) structures project to the main and to the accessory olfactory bulbs thus providing the possibility of simultaneous modulation and interaction of both systems at different stages of chemosensory processing.

Keywords: chemical senses, olfactory system, tract-tracing, vomeronasal system

\section{INTRODUCTION}

Two main nasal chemical senses, the olfactory and the vomeronasal systems, have evolved in most vertebrates to detect chemical substances (Taniguchi and Saito, 2011; Ubeda-Banon et al., 2011). In mammals, these systems begin in the olfactory and vomeronasal epithelia that project to the main and accessory olfactory bulbs which in turn send projections to the olfactory and vomeronasal cortices, respectively (Devor, 1976; Skeen and Hall, 1977; Turner et al., 1978; Scott et al., 1980; Kosel et al., 1981; Meyer, 1981; Shammah-Lagnado and Negrao, 1981; Carmichael et al., 1994; Jansen et al., 1998; Mohedano-Moriano et al., 2005; Martinez-Marcos and Halpern, 2006; Gutierrez-Castellanos et al., 2010).

In the 1970's, the observation that secondary olfactory and vomeronasal projections were parallel led to the dual olfactory hypothesis, according to which the olfactory and vomeronasal systems constituted two different parallel anatomical and functional pathways (Winans and Scalia, 1970; Raisman, 1972; Scalia and Winans, 1975). The main olfactory system would be devoted to the perception of airborne chemicals such as odorants, whereas the vomeronasal system would be specialized for the detection of biologically relevant molecules of high molecular weight such as pheromones, which evoke species-specific behavioral and/or physiological responses (Halpern, 1987). The data, however, have demonstrated that this hypothesis is an oversimplification (Halpern and Martinez-Marcos, 2003; Restrepo et al., 2004; Spehr et al., 2006b) since the olfactory and vomeronasal system interact both physiologically (Licht and Meredith, 1987; Peele et al., 2003; Lin et al., 2004; Trinh and Storm, 2004; Xu et al., 2005; Spehr et al., 2006a; Wang et al., 2006; Keller et al., 2009) and 
anatomically (Pro-Sistiaga et al., 2007, 2008; Kang et al., 2009, 2011a; Mucignat-Caretta, 2010).

Apart from olfactory- and vomeronasal-recipient areas in the telencephalon, olfactory, and vomeronasal inputs converge in areas classically considered olfactory-recipient (nucleus of the lateral olfactory tract, anterior cortical amygdaloid nucleus, and cortex-amygdala transition zone) or vomeronasal-recipient (ventral anterior amygdala, bed nucleus of the accessory olfactory tract, and anteroventral medial amygdaloid nucleus) (Pro-Sistiaga et al., 2007; Kang et al., 2009, 2011b; MartinezMarcos, 2009). Further, tertiary olfactory (Ubeda-Banon et al., 2007) and vomeronasal (Ubeda-Banon et al., 2008) projections also converge in the ventral striatum.

In many mammals, the vomeronasal system, in turn, has been demonstrated to be anatomically and functionally dichotomous (Halpern et al., 1998a,b). Two classes of vomeronasal receptor neurons, apically and basally placed in the sensory epithelium, express Gi2 $\alpha$ and Go $\alpha$ proteins (Berghard and Buck, 1996; Jia and Halpern, 1996), V1R and V2R vomeronasal receptors (Dulac and Axel, 1995; Herrada and Dulac, 1997; Matsunami and Buck, 1997; Ryba and Tirindelli, 1997), respond to different stimuli (Leinders-Zufall et al., 2000, 2004) and project to the anterior and posterior accessory olfactory bulb (Belluscio et al., 1999; Rodriguez et al., 1999), respectively. The two portions of the accessory olfactory bulb have been demonstrated to show not only convergent (Von Campenhausen and Mori, 2000; Salazar and Brennan, 2001) but differential projections to the vomeronasal amygdala (Martinez-Marcos and Halpern, 1999b; Mohedano-Moriano et al., 2007), which in turn are separately preserved to the hypothalamus (Mohedano-Moriano et al., 2008).

Common traits to all olfactory- and vomeronasal-recipient structures are reciprocal centrifugal projections to the main and accessory olfactory bulbs, respectively. The main olfactory bulb receives afferent connections from a number of olfactory-recipient structures (anterior olfactory nucleus, olfactory tubercle, piriform cortex, nucleus of the lateral olfactory tract, anterior cortical amygdala, posterolateral cortical amygdala, and lateral entorhinal cortex), hippocampus (ventral CA1) as well as from neuromodulatory centers (nucleus of the diagonal band, locus coeruleus, and dorsal raphe nucleus) (Price and Powell, 1970; Raisman, 1972; Barber and Field, 1975; Broadwell and Jacobowitz, 1976; Davis et al., 1978; de Olmos et al., 1978; Macrides et al., 1981; Barber, 1982; Luskin and Price, 1983; Shipley and Adamek, 1984; Zheng et al., 1987; Cenquizca and Swanson, 2007; Matsutani and Yamamoto, 2008; Fletcher and Chen, 2010). Centrifugal inputs have been demonstrated to be essential in the formation of odor-reward associations (Kiselycznyk et al., 2006) as well as to provide inputs to new born cells arriving to the main olfactory bulb (Mouret et al., 2009).

Afferents to the accessory olfactory bulb arise from the vomeronasal-recipient structures (medial amygdaloid nucleus, posteromedial cortical amygdaloid nucleus, bed nucleus of the accessory olfactory tract, and bed nucleus of the stria terminalis), hippocampal formation (ventral subiculum and CA1) as well as from the brainstem (locus coeruleus and dorsal raphe nucleus) (Raisman, 1972; Barber and Field, 1975; Broadwell and
Jacobowitz, 1976; Davis et al., 1978; de Olmos et al., 1978; Barber, 1982; Martinez-Marcos and Halpern, 1999a; Cenquizca and Swanson, 2007; de la Rosa-Prieto et al., 2009). Some of these centrifugal afferents (Brennan et al., 1990; Keverne and Brennan, 1996) as well as the addition of new neurons to the accessory olfactory bulb (Oboti et al., 2011) have been demonstrated to be critical for pregnancy block olfactory memory.

As far as we know, the possibility that olfactory-recipient structures project to the accessory olfactory bulb; that vomeronasalrecipient structures project to the main olfactory bulb; or that mixed chemosensory or non-chemosensory structures project to both the main and accessory olfactory bulbs have been not specifically addressed. The aim of this work has been, therefore, to investigate potential interactions between the main and accessory olfactory systems regarding their centrifugal inputs. Further, since most of these projections have been separately investigated in different species in previous reports, we have used both rats and mice in order to have a more complete panorama of centrifugal afferents in rodents.

\section{MATERIALS AND METHODS EXPERIMENTAL ANIMALS}

Adult animals of both sexes were used in the present study: 26 Sprague-Dawley rats and 20 swiss (C57BL) mice. Animals were maintained under veterinary supervision on a $12-\mathrm{h}$ light/dark cycle at $21 \pm 2{ }^{\circ} \mathrm{C}$ with food and drink ad libitum. Experimental procedures were carried out according to the guidelines of the European Community Directive 86/609/CEE for the use of laboratory animals and with Spanish law (Real Decreto 1201/2005) under the supervision of the Ethical Committee of Animal Research of the University of Castilla-La Mancha (grant BFU2010-15729).

\section{TRACER INJECTIONS}

Animals were anesthetized by an intraperitoneal injection of a combined dose of ketamine hydrochloride (Ketolar, ParkeDavis, Madrid, $1.5 \mathrm{~mL} / \mathrm{kg}, 75 \mathrm{mg} / \mathrm{kg}$ ) and xylazine (Xilagesic, Calier, Barcelona, $0.5 \mathrm{~mL} / \mathrm{kg}, 10 \mathrm{mg} / \mathrm{kg}$ ). Eye drops (Lacryvisc, Alcon, Barcelona) were applied to prevent eye ulceration during surgery. The animals were placed in a Kopf (Tujunga, CA) stereotaxic apparatus and the skull trepanned at the intended injection site. Ionophoretic injections of dextran amines conjugated to biotin (BDA), fluorescein (FDA) or tetramethylrhodamine (RDA) (10,000 MW, lysine fixable, Molecular Probes, Eugene, OR) as well as injections of FluoroGold (FG, methanesulfonate hydroxystilbamidine, Biotium, Hayward, CA) were placed in target structures: main olfactory bulb (four rats and two mice), accessory olfactory bulb (eight rats and four mice), piriform cortex (two rats and ten mice), posteromedial cortical amygdaloid nucleus (four rats), medial amygdala (four rats) and ventral CA1 (four rats), and simultaneous injections of dextran amines conjugated to RDA and FDA into the main and accessory olfactory bulbs, respectively (four mice). Only injections centered at the intended injection site and no contaminating neighboring structures were considered. The atlases of rat (Paxinos and Watson, 2007) and mouse (Franklin and Paxinos, 2008) brain were used for this study. Dextran amines (10\% in phosphate buffered saline) 
and FG (2\% saline solution) were delivered from micropipettes (30-80 $\mu \mathrm{m}$ diameter tip) by means of positive current pulses (7/7 s, 2-7 $\mu \mathrm{A}, 8-20 \mathrm{~min}$ ).

\section{PERFUSION, CUTTING, AND TRACER DETECTION}

Five to seven days later, animals were anesthetized (as above) and perfused through the ventricle with saline solution followed by $4 \%$ paraformaldehyde. The brains were postfixed overnight and cryoprotected with $30 \%$ buffered sucrose. Parasagittal (olfactory bulbs) or frontal sections $(50 \mu \mathrm{m})$ were obtained using a freezing microtome.

For biotinylated dextran-amine detection, endogenous peroxidase activity was quenched by means of $1 \% \mathrm{H}_{2} \mathrm{O}_{2}$ (in $0.05 \mathrm{M}$ Tris buffer saline, $\mathrm{pH}$ 7.6, for $30 \mathrm{~min}$ ). Sections were incubated for $2 \mathrm{~h}$ in avidin-biotin complex (ABC elite kit, Vector, Burlingame, CA; diluted at $2 \%$ in $0.05 \mathrm{M}$ Tris buffer saline, $\mathrm{pH} 7.6$ ) and visualized with $0.02 \%$ 3,3'-diaminobenzidine (Sigma, St. Louis, MO) diluted in $0.05 \mathrm{M}$ Tris buffer $(\mathrm{pH} 8.0)$ with $0.1 \%$ ammonium nickel sulfate and $0.01 \% \mathrm{H}_{2} \mathrm{O}_{2}$. Sections were mounted, dried, stained with thionin (Panreac, Barcelona) and coverslipped with DPX (BDH Laboratory, Poole, UK).

For fluorescent tracers, sections were mounted and coverslipped with $30 \%$ glycerin in $0.4 \mathrm{M}$ potassium bicarbonate. Analysis was performed under bright-field and epifluorescence microscopy. Contrast and brightness of images were adjusted using Adobe Photoshop (San Jose, CA) 8.0.1 software and arranged and lettered using Canvas 11.0 (Deneba, Miami, FL).

\section{RESULTS}

\section{INJECTIONS INTO THE MAIN OLFACTORY BULB}

In order to analyze afferent connections to the main olfactory bulb in our own material experiments using FG and dextran amine-labeled RDA were carried out. The pattern of labeling was consistent in the different experiments performed.

Injections of FG yielded a large, poorly defined injection site in the granule cell layer of the main olfactory bulb of rats (as example see case R0207, $7.5 \mathrm{~mm}$ from Bregma, Figure 1A). As expected, a number of retrogradely labeled cells were observed in the anterior olfactory nucleus (Figure 1B), nucleus of the diagonal band (Figure 1C), layers 2 and 3 of the rostral piriform cortex (Figure 1D), olfactory tubercle (Figure 1E), anterior amygdaloid area, and faintly labeled neurons in layers 2 and 3 of the nucleus of the lateral olfactory tract, anterior cortical amygdaloid nucleus, cortex-amygdala transition area, and caudal piriform cortex (Figure 1F). Labeled cells were present in the anterodorsal medial amygdaloid nucleus $(-1.8 \mathrm{~mm}$ from Bregma, Figure 1G) and slightly labeled cells were also observed in the posterolateral cortical amygdaloid nucleus (not shown) and lateral entorhinal cortex (Figure $\mathbf{1 H}$ ).

Injections of dextran amine-labeled RDA into the granule cell layer of the main olfactory bulb of rats gave rise a similar pattern of labeling, but a considerably reduced injection site (as example see case R4505, $6.6 \mathrm{~mm}$ from Bregma, Figure 2A, $7.5 \mathrm{~mm}$ from Bregma) and consequently to a scarcer retrograde labeling as compared to FG injections. As in the previous case, labeled cells could be observed in the anterior olfactory nucleus (not shown), nucleus of the diagonal band (Figure 2B), rostral piriform cortex
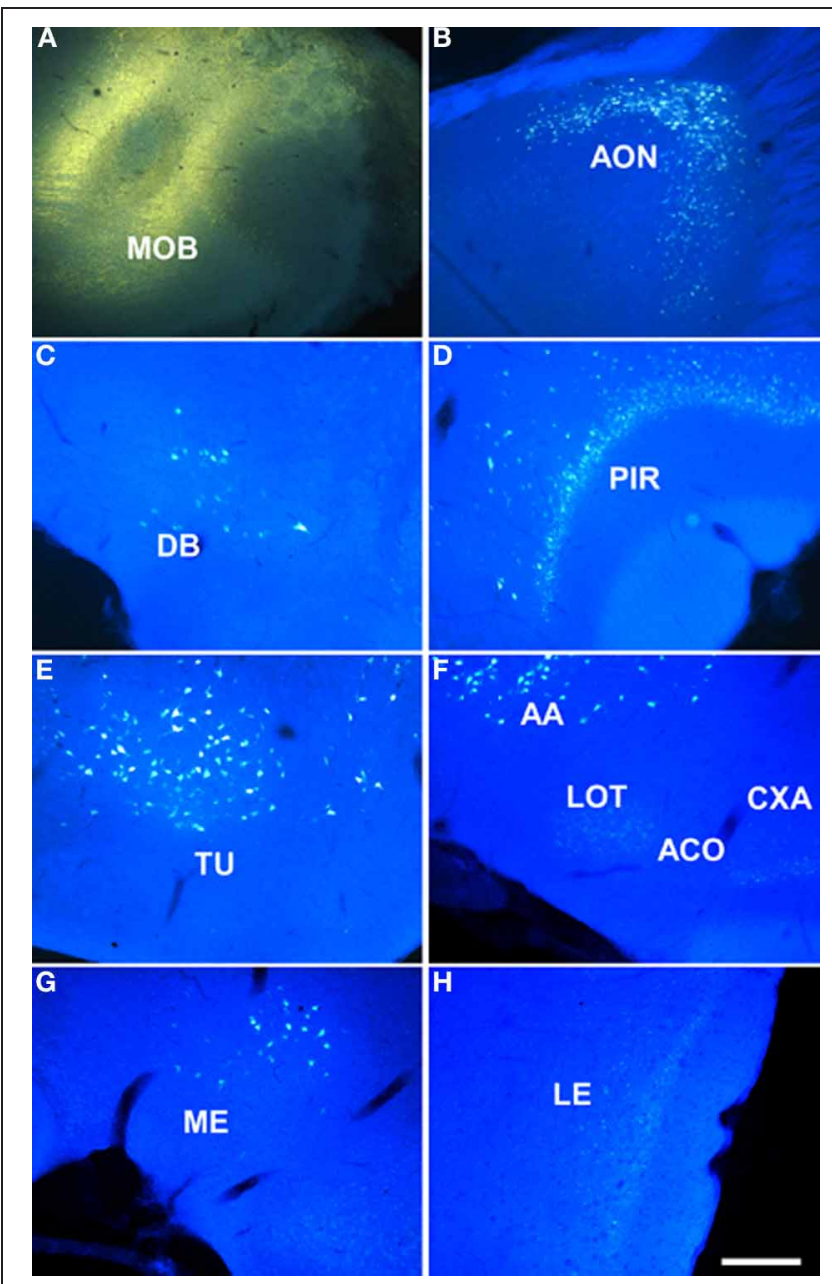

FIGURE 1 | Sagittal (A,B) and coronal sections (C-H) from rostral to caudal levels of the telencephalic hemisphere showing the resulting labeling $(B-H)$ after a FluoroGold injection in the rat main olfactory bulb (A). Abbreviations: $A A$, anterior amygdala; $A C O$, anterior cortical amygdala; $\mathrm{AON}$, anterior olfactory nucleus; CXA, cortex-amygdala transition zone; DB, nucleus of the diagonal band; LE, lateral entorhinal cortex; LOT, nucleus of the lateral olfactory tract; $\mathrm{ME}$, medial amygdala; $\mathrm{MOB}$, main olfactory bulb; PIR, piriform cortex; PLCO, posterolateral cortical amygdala; TU, olfactory tubercle. Scale bar for A: $1000 \mu \mathrm{m}, \mathbf{B}-\mathbf{H}: 400 \mu \mathrm{m}$.

(Figure 2C), olfactory tubercle (not shown), anterior amygdaloid area, nucleus of the lateral olfactory tract, anterior cortical amygdaloid nucleus, cortex-amygdala transition zone (Figures 2D,E), caudal piriform cortex (Figure 2F), anterodorsal medial amygdaloid nucleus ( $-2.0 \mathrm{~mm}$ from Bregma, Figure 2G), posterolateral cortical amygdaloid nucleus (not show) and lateral entorhinal cortex (Figure 2H).

\section{INJECTIONS INTO THE ACCESSORY OLFACTORY BULB}

Given the small size of the accessory olfactory bulb, dextranamines were used as neural tracers. All cases with injections in the accessory olfactory bulb yielded a similar pattern of labeling.

Injections of dextran amine-labeled RDA involving the mitral and granule cell layer of the accessory olfactory bulb of rats 


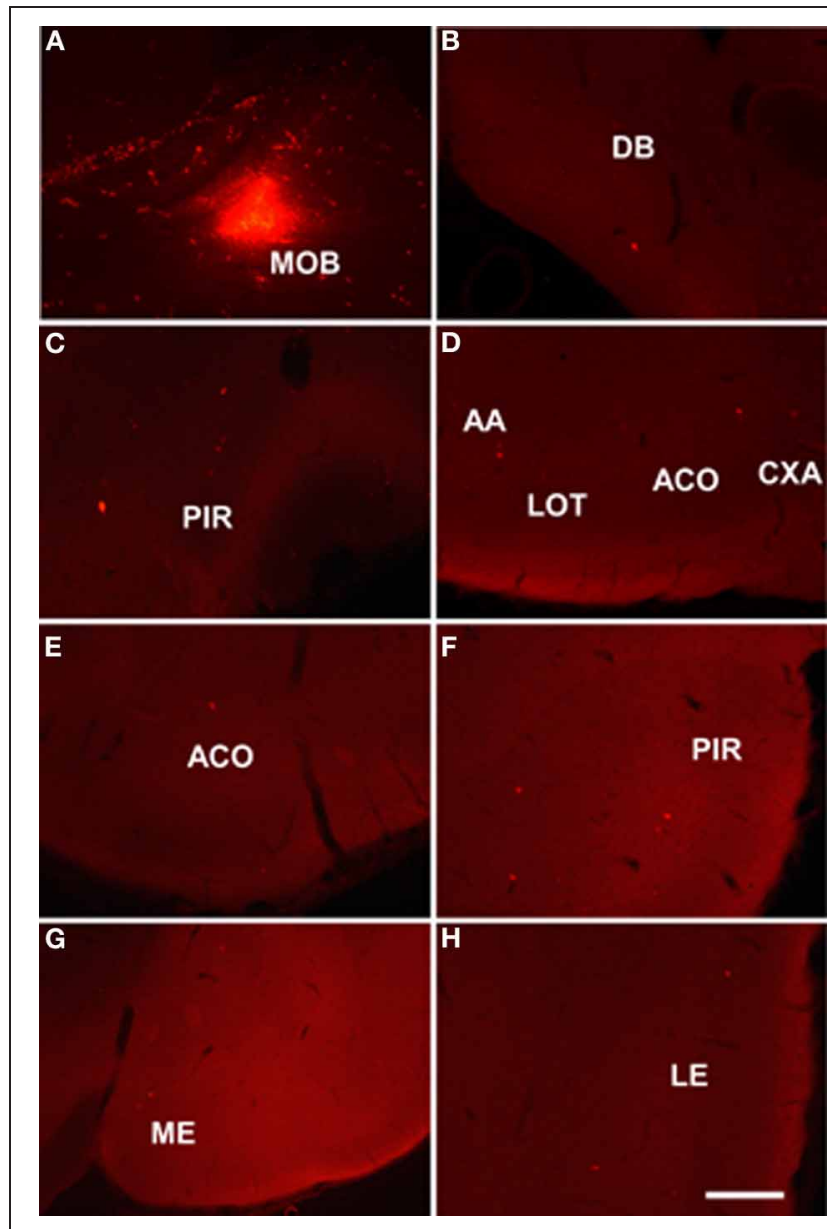

FIGURE 2 | Sagittal (A) and coronal sections (B-H) from rostral to caudal levels of the telencephalic hemisphere showing the resulting labeling (B-H) after a dextran-amine labeled tetramethylrhodamine injection in the rat main olfactory bulb (A). Abbreviations: $A A$, anterior amygdala; $\mathrm{ACO}$, anterior cortical amygdala; $\mathrm{AON}$, anterior olfactory nucleus; CXA, cortex-amygdala transition zone; $\mathrm{DB}$, nucleus of the diagonal band; $L E$, lateral entorhinal cortex; LOT, nucleus of the lateral olfactory tract; $M E$, medial amygdala; MOB, main olfactory bulb; PIR, piriform cortex; PLCO, posterolateral cortical amygdala. Scale bar for A: $800 \mu \mathrm{m}, \mathbf{B}-\mathbf{H}: 400 \mu \mathrm{m}$. (as example see case R8205, 6.2 mm from Bregma, Figure 3A) gave rise to scarce retrograde labeled neurons in the nucleus of the diagonal band (Figure 3B), rostral pirirform cortex (Figure 3C), bed nuclei of the stria terminalis (Figure 3D) and accessory olfactory tract (Figure 3E), anterodorsal medial amgydaloid nucleus $(-1.8 \mathrm{~mm}$ from Bregma, Figure $3 \mathbf{F})$, posteromedial cortical amygdaloid nucleus (Figure 3G), and the ventral portion of the subiculum and CA1 (Figure 3H).

It has also to be noted that the dorsal portion of the olfactory tract, through which course centripetal and centrifugal axons to the main olfactory bulb, is situated between the mitral and granule cell layer of the accessory olfactory bulb (Larriva-Sahd, 2008). Accordingly, it cannot rule out the possibility that injections into the accessory olfactory bulb involve these axons. Therefore, anterograde tracing experiments (sections "Injections in the piriform cortex, Injections in the posteromedial cortical amygdala,

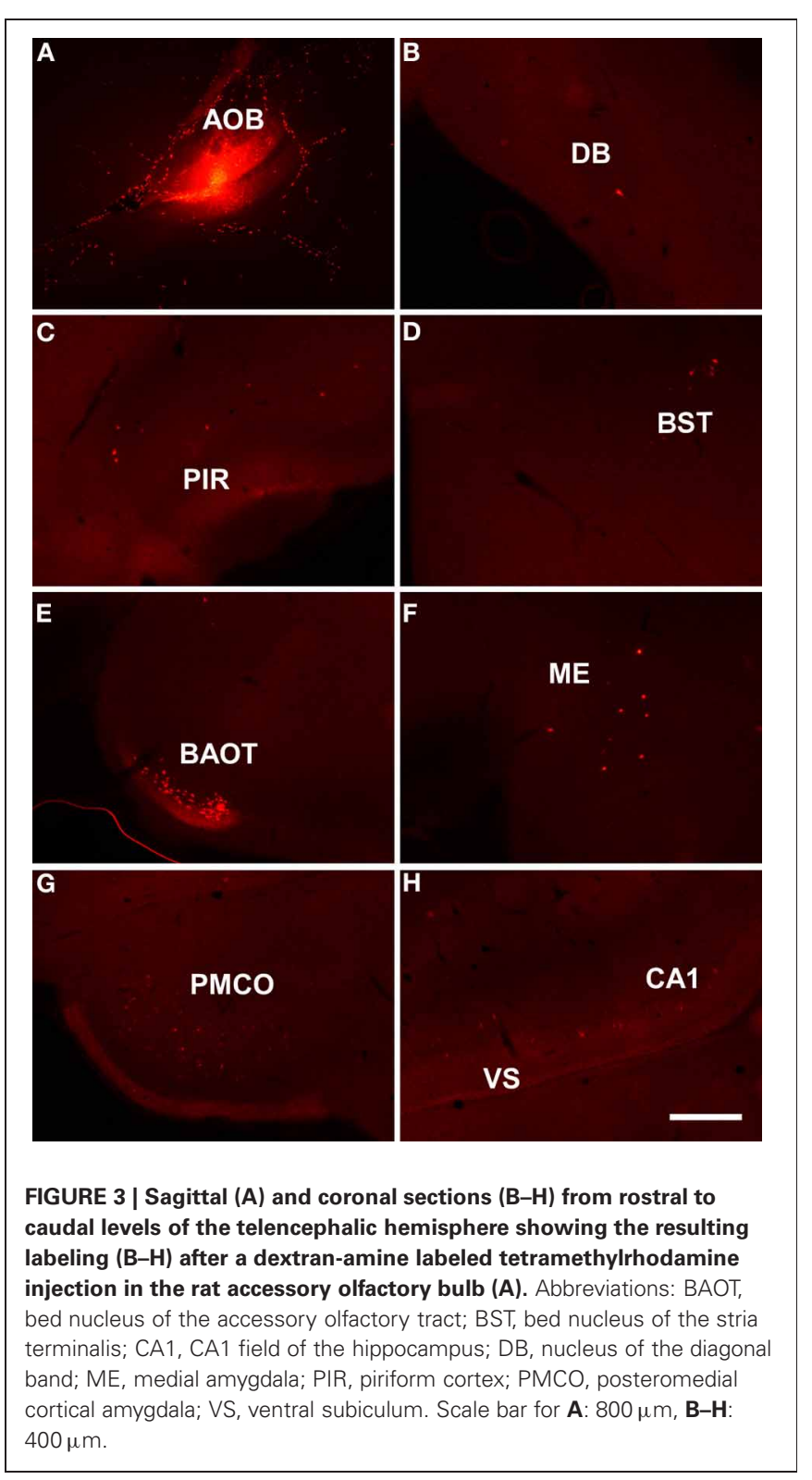

Injections in the anterodorsal medial amygdaloid nucleus, and Injections in the hippocampal formation") should confirm retrograde tracing results in order to fully discriminate afferent connections either to the main bulb, accessory bulb or both.

\section{INJECTIONS IN THE MAIN AND ACCESSORY OLFACTORY BULBS}

In order to compare the centrifugal afferent connections to the main and accessory olfactory bulb, four mice were simultaneously injected with dextran amine-labeled RDA into the main olfactory bulb and dextran amine-labeled FDA into the accessory olfactory bulb. However, these latter injections were not exclusively restricted to the accessory olfactory bulb or affected the dorsal portion of the olfactory tract running through the accessory olfactory bulb. Labeling was consistent to that observed after injections into the main or accessory olfactory bulb in previous experiments. 

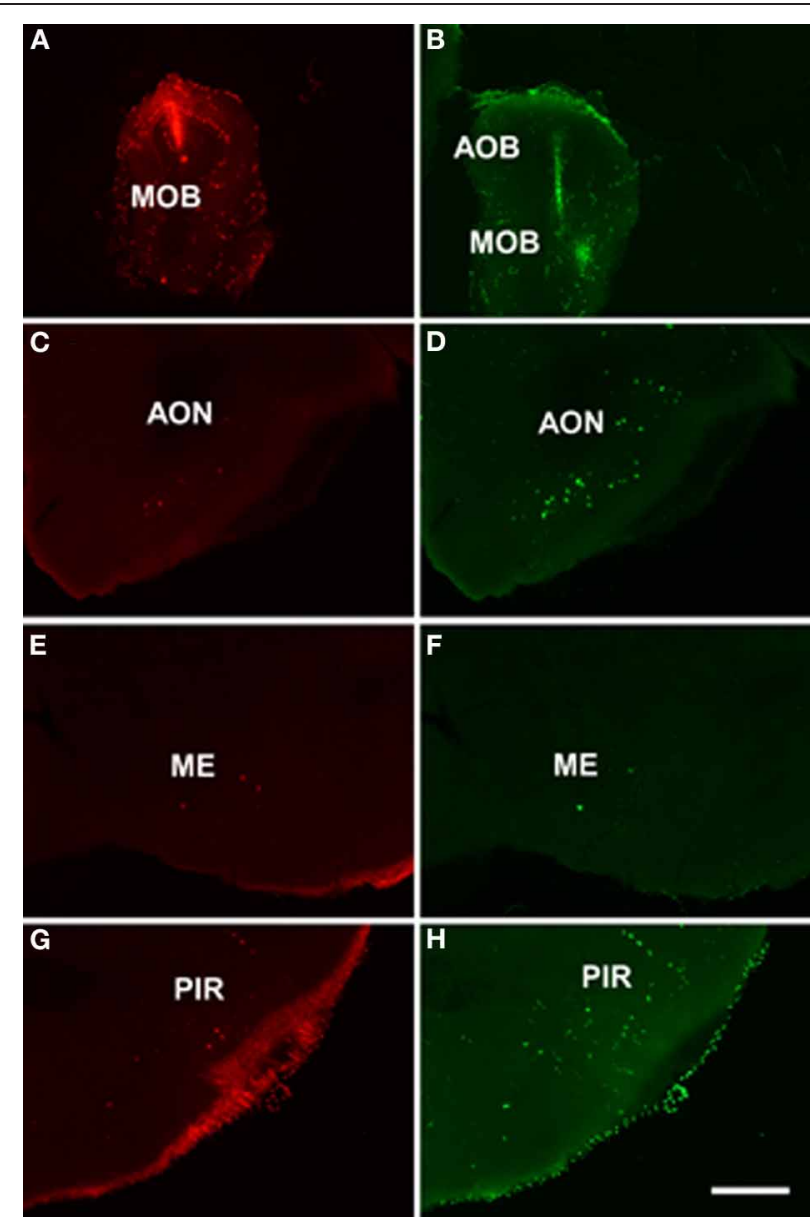

FIGURE 4 | Coronal sections from rostral to caudal levels of the telencephalic hemisphere showing the resulting labeling (C,E,G and $\mathrm{D}, \mathrm{F}, \mathrm{H})$ after a dextran-amine labeled tetramethylrhodamine injection in the mouse main olfactory bulb (A) and a dextran-amine labeled fluorescein injection in the mouse main and accessory olfactory bulbs (B), respectively. Abbreviations: $A O B$, accessory olfactory bulb; $A O N$, anterior olfactory nucleus; $\mathrm{ME}$, medial amygdala; $\mathrm{MOB}$, main olfactory bulb; PIR, piriform cortex. Scale bar for A, B: $800 \mu \mathrm{m}, \mathbf{C}-\mathbf{H}: 400 \mu \mathrm{m}$.

As example, case RN21312 showed a dextran amine-labeled RDA injection in the main olfactory bulb (4.3 $\mathrm{mm}$ from Bregma, Figure 4A) and a dextran amine-labeled FDA injection in the accessory olfactory bulb, but that also contaminated the main olfactory bulb ( $3.5 \mathrm{~mm}$ from Bregma, Figure 4B). As expected, labeling was present in olfactory and vomeronasal structures such as the anterior olfactory nucleus (Figures 4C,D), anterodorsal medial amygdaloid nuelus $(-1.0 \mathrm{~mm}$ from Bregma, Figures 4E,F), and piriform cortex (Figures 4G,H).

\section{INJECTIONS IN THE PIRIFORM CORTEX}

Injections of biotinylated dextran-amine in the rat piriform cortex gave rise to a similar pattern of labeling (as example see case R10307, $-0.2 \mathrm{~mm}$ from Bregma, Figure 5A) including anterogradely labeled fibers in the ventral and dorsal portions of the lateral olfactory tract (Figure 5B). Labeled fibers showing varicosities could be observed throughout the granule cell layer

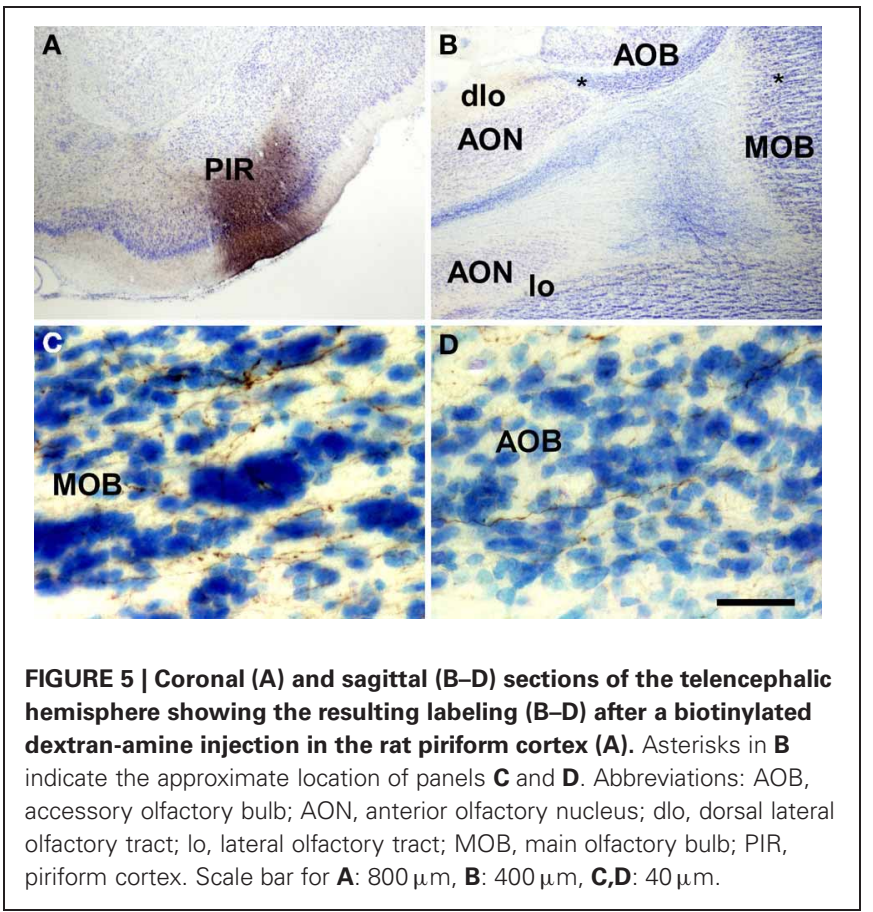

of the main olfactory bulb (Figure 5C). A number of labeled fibers were also present in the granule cell layer of the accessory olfactory bulb (Figure 5D).

\section{INJECTIONS IN THE POSTEROMEDIAL CORTICAL AMYGDALA}

Injections of biotinylated dextran-amine in the rat posteromedial cortical amygdala gave rise to a consistent labeling (as example see case R9207, $-4.4 \mathrm{~mm}$ from Bregma, Figure 6A) with fibers reaching the accessory olfactory bulb where they form a dense plexus of labeled axons showing varicosities in the granule cell layer (Figure 6B). A number of labeled beaded axons could also be observed in the granule cell layer of the main olfactory bulb (Figure 6C). Labeling was observed in both anterior and posterior portions of the accessory olfactory bulb.

\section{INJECTIONS IN THE ANTERODORSAL MEDIAL AMYGDALOID NUCLEUS}

Injections of biotinylated dextran-amine in the rat anterodorsal medial amygdaloid nucleus yielded a similar labeling (as example see case R8305, - $1.8 \mathrm{~mm}$ from Bregma, Figure 7A) including labeled fibers reaching the accessory olfactory bulb where smooth axons could be observed in the mitral cell layer of the accessory olfactory bulb (Figure 7B). Labeled fibers were not observed in the granule cell layer of the accessory olfactory bulb or main olfactory bulb.

\section{INJECTIONS IN THE HIPPOCAMPAL FORMATION}

Injections of biotinylated dextran-amine in the rat ventral subiculum gave rise to comparable labeling (as example see case R10207, $-4.8 \mathrm{~mm}$ from Bregma, Figure 7C) with labeled fibers reaching the accessory olfactory bulb where fine, beaded axons could be observed in the granule cell layer (Figure 7D). Labeled fibers were not observed in the granule cell layer of the main olfactory bulb. 


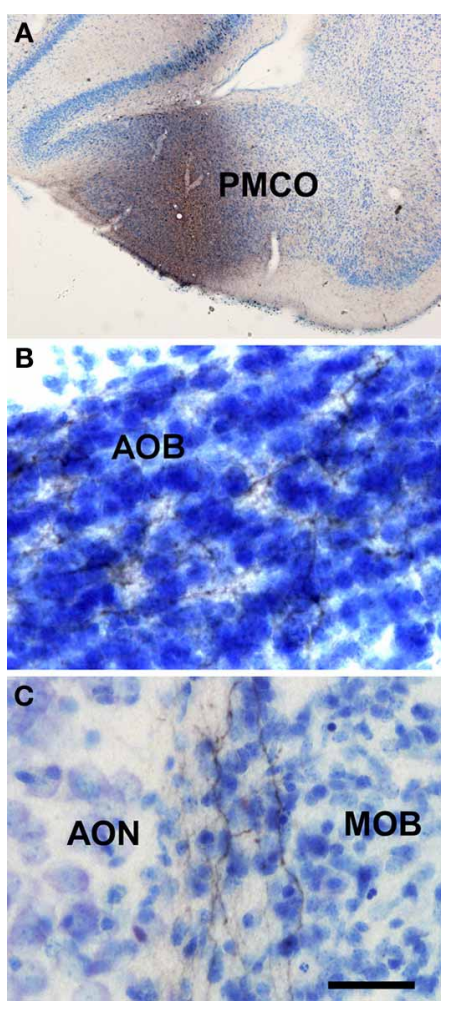

FIGURE 6 | Coronal (A) and sagittal (B,C) sections of the telencephalic hemisphere showing the resulting labeling $(B, C)$ after a biotinylated dextran-amine injection in the rat posteromedial cortical amygdala (A). Abbreviations: $A O B$, accessory olfactory bulb; $A O N$, anterior olfactory nucleus; $\mathrm{MOB}$, main olfactory bulb; PMCO, posteromedial cortical amygdala. Scale bar for A: $800 \mu \mathrm{m}, \mathbf{B}, \mathbf{C}: 40 \mu \mathrm{m}$.

\section{DISCUSSION}

The aim of this work has been to investigate the possibility that olfactory and vomeronasal system can interact anatomically regarding their centrifugal telencephalic afferent connections. Namely, the possibility that olfactory-recipient structures project to the accessory olfactory bulb; that vomeronasal-recipient structures project to the main olfactory bulb; or, that mixed chemosensory or non-chemosensory structures project to both the main and accessory olfactory bulbs.

Our results after retrograde tracing experiments in the main and accessory olfactory bulbs and confirmation anterograde tracing experiments show that, as already reported, olfactoryrecipient structures (the anterior olfactory nucleus, the piriform cortex, the cortex-amygdala transition zone, the olfactory tubercle, the nucleus of the lateral olfactory tract, the anterior, anterior cortial and posterolateral cortical amygdalae, and the lateral entorhinal cortex) project back to the main olfactory bulb; and that vomeronasal-recipient structures (the bed nuclei of the stria terminalis and of the accessory olfactory tract and the anterior medial and posteromedial cortical amygdalae) project back to the accessory olfactory bulb. In addition, a pure olfactory-recipient such as the piriform cortex structure also projects to the accessory olfactory bulb; a pure vomeronasal-recipient structure such as the
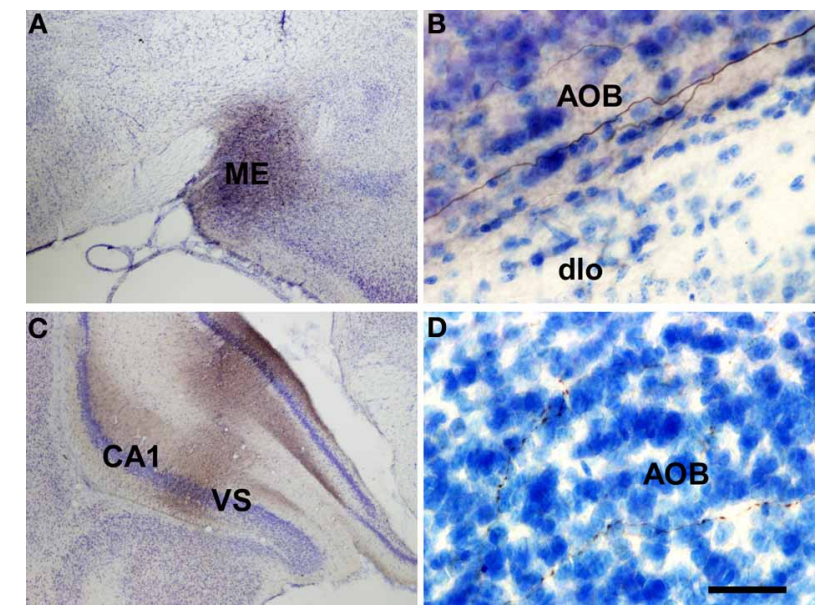

FIGURE 7 | Coronal $(A, C)$ and sagittal $(B, D)$ sections of the telencephalic hemisphere showing the resulting labeling $(B, D)$ after biotinylated dextran-amine injections in the rat anterodorsal medial amygdaloid nucleus (A) and ventral subiculium (C), respectively. Abbreviations: AOB, accessory olfactory bulb; CA1, field CA1 of the hippocampus; dlo, dorsal lateral olfactory tract; ME, medial amygdala; VS, ventral subiculum. Scale bar for A: $800 \mu \mathrm{m}, \mathbf{B}, \mathbf{C}: 40 \mu \mathrm{m}$.

posteromedial cortical amygdaloid nucleus could also project to the main olfactory bulb; a mixed chemosensory-recipient structure such as the anterodorsal medial amygdaloid nucleus project to both the main and accessory olfactory bulb; and, finally, nonchemosensory structures such as the nucleus of the diagonal band project to both bulbs and the ventral subiculum and CA1 project to the accessory olfactory bulb (Table 1).

\section{NEUROANATOMICAL REMARKS}

In general, our data are in agreement with previous studies regarding the centrifugal telencephalic afferent connections to the main olfactory bulb arising from the anterior olfactory nucleus, piriform cortex, nucleus of the diagonal band, the olfactory tubercle, the nucleus of the lateral olfactory tract, the anterior and posterolateral cortical amygdalae, and the lateral entorhinal cortex (Price and Powell, 1970; Raisman, 1972; Broadwell and Jacobowitz, 1976; Davis et al., 1978; de Olmos et al., 1978; Macrides et al., 1981; Luskin and Price, 1983; Shipley and Adamek, 1984; Matsutani and Yamamoto, 2008).

Similarly, our results confirm previous results in the literature regarding telencephalic centrifugal afferent connections to the accessory olfactory bulb arising from the nucleus of the accessory olfactory tract, bed nucleus of the stria terminalis, and medial and posteromedial cortical amygdalae (Raisman, 1972; Barber and Field, 1975; Broadwell and Jacobowitz, 1976; Davis et al., 1978; de Olmos et al., 1978; Barber, 1982; Martinez-Marcos and Halpern, 1999a; Fan and Luo, 2009). Early reports showed a laminar pattern of afferent connections to the accessory olfactory bulb ending in the granule or internal plexiform layers and originating either in the posteromedial cortical amygdala - and coursing through the stria terminalis-or originating in medial amygdala and bed nucleus of the accessory olfactory tract-and traveling 
Table 1 | Summary chart of main results.

\begin{tabular}{|c|c|c|}
\hline Injection site & Retrograde labeling & Anterograde labeling \\
\hline Main olfactory bulb & $\begin{array}{l}\text { Anterior olfactory nucleus } \\
\text { Nucleus of the diagonal band } \\
\text { Piriform cortex } \\
\text { Olfactory tubercle } \\
\text { Anterior amygdaloid area } \\
\text { Nucleus of the lateral olfactory tract } \\
\text { Anterior cortical amygdaloid nucleus } \\
\text { Cortex-amygdala transition area } \\
\text { Anterodorsal medial amygdaloid nucleus } \\
\text { Posterolateral cortical amygdaloid nucleus } \\
\text { Lateral entorhinal cortex }\end{array}$ & \\
\hline Accessory olfactory bulb & $\begin{array}{l}\text { Nucleus of the diagonal band } \\
\text { Piriform cortex } \\
\text { Bed nucleus of the stria terminalis } \\
\text { Bed nucleus of the accessory olfactory tract } \\
\text { Anterodorsal medial amygdaloid nucleus } \\
\text { Posteromedial cortical amygdaloid nucleus } \\
\text { Ventral subiculum and CA1 }\end{array}$ & \\
\hline Piriform cortex & & $\begin{array}{l}\text { Granule cell layer of the main olfactory bulb } \\
\text { Granule cell layer of the accessory olfactory bulb }\end{array}$ \\
\hline Posteromedial cortical amygdaloid nucleus & & $\begin{array}{l}\text { Granule cell layer of the accessory olfactory bulb } \\
\text { Granule cell layer of the main olfactory bulb }\end{array}$ \\
\hline Anterodorsal medial amygaloid nucleus & & Mitral cell layer of the accessory olfactory bulb \\
\hline Ventral subiculum & & Granule cell layer of the accessory olfactory bulb \\
\hline
\end{tabular}

through the accessory olfactory tract-respectively (Barber and Field, 1975; Barber, 1982). Later, it has been reported a centrifugal GABAergic projection from the bed nucleus of the stria terminalis to the mitral cell layer and another centrifugal glutamatergic projection from the vomeronasal amygdala to the granule cell layer of the accessory olfactory bulb (Fan and Luo, 2009). Our results are in agreement with previous studies and there are likely at least two centrifugal pathways to the accessory olfactory bulb originating from the bed nucleus of the stria terminalis, bed nucleus of the accessory olfactory bulb and anterodorsal medial amygdala and from the rest of the medial amygdala and posteromedial cortical amygdala.

In addition, our retrograde (Figures 1, 2 and 3) and anterograde (Figure 5) tracing experiments demonstrate that the piriform cortex, a pure olfactory-recipient structure, project back to both the main and accessory olfactory bulbs. Since the dorsal portion of the olfactory tract courses between the mitral and granule cell layers of the accessory olfactory bulb, the possibility that axons traveling to the main olfactory bulb were affected in retrograde tracing experiments aimed at the accessory olfactory bulb cannot be discarded (Martinez-Marcos and Halpern, 1999a) (Figure 3). Anterograde experiments, however, confirm a projection from the pirifrom cortex to the granule cell layer of the accessory olfactory bulb (Figure 5).

Our results after injection centered in the posteromedial cortical amygdaloid nucleus suggest a possible projection from this vomeronasal structure to the main olfactory bulb (Figure 6). The fact that retrograde tracing experiments in the main olfactory bulb do not confirm this projection (Figures 1 and 2) indicate that further experiments are needed prior to ratify it.

Interestingly, our data after retrograde tracing experiments show that the anterior medial amygdaloid nucleus, which has been reported to be a mixed chemosensory structure (anteroventral division) since it receives both olfactory and vomeronasal inputs (Pro-Sistiaga et al., 2007) critical for sexual behaviors (Kang et al., 2009, 2011b), project back (anterodorsal division) to both the main and accessory olfactory bulbs (Figures 1, 2, 3 and 4). Our anterograde tracing experiments, however, do not confirm this projection (Figure 7). Our interpretation is that this discrepancy is probably due to the fact that the injections in the anterodorsal medial amygdaloid nucleus are not massive enough to fill up the small number of cells in this structure projecting to the bulbs. Therefore, the anterior medial amgydaloid nucleus could be a mixed chemosensory structure not only regarding the afferent but also the efferent connections to the bulbs. The importance of this pathway is supported by behavioral data (Martel and Baum, 2009).

The olfactory bulbs receive a number of non-chemosensory, modulatory centrifugal inputs (Matsutani and Yamamoto, 2008). Namely, our results show a minor telencephalic projection arising from the nucleus of the diagonal band to the main (Figures 1 and 2) and accessory (Figure 3) bulbs. This projection appears to be cholinergic (Macrides et al., 1981; Zaborszky et al., 1986; Zheng et al., 1987; Kunze et al., 1992) and it has a critical role in olfactory learning (Fletcher and Chen, 2010). In fact, cholinergic inputs from the nucleus of the diagonal band are established 
onto dendrites of newly-born granule cells in the olfactory bulbs and are essential for survival of new neurons and olfactory processing (Kiselycznyk et al., 2006; Whitman and Greer, 2007; Mouret et al., 2009).

Finally, our present results (Figures 3 and 7) and previous reports (Cenquizca and Swanson, 2007; de la Rosa-Prieto et al., 2009) confirm a projection from the ventral subiculum and CA1 to the granule cell layer of the accessory olfactory bulb. The functional significance of this projection is currently unknown.

\section{CONCLUSION}

Our results show an extent anatomical interaction between the olfactory and vomeronasal system regarding their centrifugal

\section{REFERENCES}

Barber, P. C. (1982). Adjacent laminar terminations of two centrifugal afferent pathways to the accessory olfactory bulb in the mouse. Brain Res. 245, 215-221.

Barber, P. C., and Field, P. M. (1975). Autoradiographic demonstration of afferent connections of the accessory olfactory bulb in the mouse. Brain Res. 85, 201-203.

Belluscio, L., Koentges, G., Axel, R., and Dulac, C. (1999). A map of pheromone receptor activation in the mammalian brain. Cell 97, 209-220.

Berghard, A., and Buck, L. B. (1996). Sensory transduction in vomeronasal neurons: evidence for $G$ alpha o, G alpha i2, and adenylyl cyclase II as major components of a pheromone signaling cascade. J. Neurosci. 16, 909-918.

Brennan, P., Kaba, H., and Keverne, E. B. (1990). Olfactory recognition: a simple memory system. Science 250, 1223-1226.

Broadwell, R. D., and Jacobowitz, D. M. (1976). Olfactory relationships of the telencephalon and diencephalon in the rabbit. III. The ipsilateral centrifugal fibers to the olfactory bulbar and retrobulbar formations. J. Comp. Neurol. 170, 321-345.

Carmichael, S. T., Clugnet, M. C., and Price, J. L. (1994). Central olfactory connections in the macaque monkey. J. Comp. Neurol. 346, 403-434.

Cenquizca, L. A., and Swanson, L. W. (2007). Spatial organization of direct hippocampal field CA1 axonal projections to the rest of the cerebral cortex. Brain Res. Rev. 56, $1-26$.

Davis, B. J., Macrides, F., Youngs, W. M., Schneider, S. P., and Rosene, D. L. (1978). Efferents and centrifugal afferents of the main and accessory olfactory bulbs in the hamster. Brain Res. Bull. 3, 59-72. de la Rosa-Prieto, C., Ubeda-Banon, I., Mohedano-Moriano, A., ProSistiaga, P., Saiz-Sanchez, D., Insausti, R., and Martinez-Marcos, A. (2009). Subicular and CA1 hippocampal projections to the accessory olfactory bulb. Hippocampus 19, 124-129.

de Olmos, J., Hardy, H., and Heimer, L. (1978). The afferent connections of the main and the accessory olfactory bulb formations in the rat: an experimental HRP-study. J. Comp. Neurol. 181, 213-244.

Devor, M. (1976). Fiber trajectories of olfactory bulb efferents in the hamster. J. Comp. Neurol. 166, 31-47.

Dulac, C., and Axel, R. (1995). A novel family of genes encoding putative pheromone receptors in mammals. Cell 83, 195-206.

Fan, S., and Luo, M. (2009). The organization of feedback projections in a pathway important for processing pheromonal signals. Neuroscience 161, 489-500.

Fletcher, M. L., and Chen, W. R. (2010). Neural correlates of olfactory learning: critical role of centrifugal neuromodulation. Learn. Mem. 17, 561-570.

Franklin, K. B. J., and Paxinos, G. (2008). The Mouse Brain in Stereotaxic Coordinates. San Diego, CA: Academic Press.

Gutierrez-Castellanos, N., MartinezMarcos, A., Martinez-Garcia, F., and Lanuza, E. (2010). Chemosensory function of the amygdala. Vitam. Horm. 83, 165-196. and function of the vomeronasal system. Annu. Rev. Neurosci. 10, 325-362.

Halpern, M., Jia, C., and Shapiro, L. S. (1998a). Segregated pathways in the vomeronasal system. Microsc. Res. Tech. 41, 519-529.

Halpern, M., and Martinez-Marcos, A. (2003). Structure and function of
Halpern, M. (1987). The organization

connections. Apart from feed-back projections from olfactoryand vomeronasal-recipient structures to the main and accessory olfactory bulbs, respectively, a number of dual connections to both bulbs are presented from olfactory, vomeronasal, mixed, and non-chemosensory structures. Globally, these results further stress the idea of mutual interactions between the olfactory and the vomeronasal systems.

\section{ACKNOWLEDGMENTS}

This study was supported by the Spanish Ministry of Science and Innovation-FEDER (BFU2010-15729) and the Autonomous Government of Castilla-La Mancha-FEDER (PEIC11-00454490).

the vomeronasal system: an update. Prog. Neurobiol. 70, 245-318.

Halpern, M., Shapiro, L. S., and Jia, C. (1998b). Heterogeneity in the accessory olfactory system. Chem. Senses 23, 477-481.

Herrada, G., and Dulac, C. (1997). A novel family of putative pheromone receptors in mammals with a topographically organized and sexually dimorphic distribution. Cell 90, 763-773.

Jansen, H. T., Iwamoto, G. A., and Jackson, G. L. (1998). Central connections of the ovine olfactory bulb formation identified using wheat germ agglutinin-conjugated horseradish peroxidase. Brain Res. Bull. 45, 27-39.

Jia, C., and Halpern, M. (1996). Subclasses of vomeronasal receptor neurons: differential expression of $\mathrm{G}$ proteins ( $\mathrm{Gi}$ alpha 2 and G(o alpha)) and segregated projections to the accessory olfactory bulb. Brain Res. 719, 117-128.

Kang, N., Baum, M. J., and Cherry, J. A. (2009). A direct main olfactory bulb projection to the 'vomeronasal' amygdala in female mice selectively responds to volatile pheromones from males. Eur. J. Neurosci. 29, 624-634.

Kang, N., Baum, M. J., and Cherry, J. A. (2011a). Different profiles of main and accessory olfactory bulb mitral/tufted cell projections revealed in mice using an anterograde tracer and a whole-mount, flattened cortex preparation. Chem. Senses 36, 251-260.

Kang, N., McCarthy, E. A., Cherry, J. A., and Baum, M. J. (2011b). A sex comparison of the anatomy and function of the main olfactory bulb-medial amygdala projection in mice. Neuroscience 172, 196-204.

Keller, M., Baum, M. J., Brock, O., Brennan, P. A., and Bakker, J.
(2009). The main and the accessory olfactory systems interact in the control of mate recognition and sexual behavior. Behav. Brain Res. 200 268-276.

Keverne, E. B., and Brennan, P. A. (1996). Olfactory recognition memory. J. Physiol. Paris 90, 399-401.

Kiselycznyk, C. L., Zhang, S., and Linster, C. (2006). Role of centrifugal projections to the olfactory bulb in olfactory processing. Learn. Mem. $13,575-579$.

Kosel, K. C., Van Hoesen, G. W., and West, J. R. (1981). Olfactory bulb projections to the parahippocampal area of the rat. J. Comp. Neurol. 198, 467-482.

Kunze, W. A., Shafton, A. D., Kem, R. E., and McKenzie, J. S. (1992). Intracellular responses of olfactory bulb granule cells to stimulating the horizontal diagonal band nucleus. Neuroscience 48, 363-369.

Larriva-Sahd, J. (2008). The accessory olfactory bulb in the adult rat: a cytological study of its cell types, neuropil, neuronal modules, and interactions with the main olfactory system. J. Comp. Neurol. 510, 309-350.

Leinders-Zufall, T., Brennan, P., Widmayer, P., Chandramani, P., Maul-Pavicic, A., Jager, M., Li, X. H., Breer, H., Zufall, F., and Boehm, T. (2004). MHC class I peptides as chemosensory signals in the vomeronasal organ. Science 306 , 1033-1037.

Leinders-Zufall, T., Lane, A. P., Puche, A. C., Ma, W., Novotny, M. V., Shipley, M. T., and Zufall, F. (2000). Ultrasensitive pheromone detection by mammalian vomeronasal neurons. Nature 405, 792-796.

Licht, G., and Meredith, M. (1987). Convergence of main and accessory olfactory pathways onto single neurons in the hamster amygdala. Exp. Brain Res. 69, 7-18. 
Lin, W., Arellano, J., Slotnick, B., and Restrepo, D. (2004). Odors detected by mice deficient in cyclic nucleotide-gated channel subunit A2 stimulate the main olfactory system. J. Neurosci. 24, 3703-3710.

Luskin, M. B., and Price, J. L. (1983). The topographic organization of associational fibers of the olfactory system in the rat, including centrifugal fibers to the olfactory bulb. J. Comp. Neurol. 216, 264-291.

Macrides, F., Davis, B. J., Youngs, W. M., Nadi, N. S., and Margolis, F. L. (1981). Cholinergic and catecholaminergic afferents to the olfactory bulb in the hamster: a neuroanatomical, biochemical, and histochemical investigation. J. Comp. Neurol. 203, 495-514.

Martel, K. L., and Baum, M. J. (2009). A centrifugal pathway to the mouse accessory olfactory bulb from the medial amygdala conveys genderspecific volatile pheromonal signals. Eur. J. Neurosci. 29, 368-376.

Martinez-Marcos, A. (2009). On the organization of olfactory and vomeronasal cortices. Prog. Neurobiol. 87, 21-30.

Martinez-Marcos, A., and Halpern, M. (1999a). Differential centrifugal afferents to the anterior and posterior accessory olfactory bulb. Neuroreport 10, 2011-2015.

Martinez-Marcos, A., and Halpern, M. (1999b). Differential projections from the anterior and posterior divisions of the accessory olfactory bulb to the medial amygdala in the opossum, Monodelphis domestica. Eur. J. Neurosci. 11, 3789-3799.

Martinez-Marcos, A., and Halpern, M. (2006). Efferent connections of the main olfactory bulb in the opossum (Monodelphis domestica): a characterization of the olfactory entorhinal cortex in a marsupial. Neurosci. Lett. 395, 51-56.

Matsunami, H., and Buck, L. B. (1997). A multigene family encoding a diverse array of putative pheromone receptors in mammals. Cell 90, 775-784.

Matsutani, S., and Yamamoto, N. (2008). Centrifugal innervation of the mammalian olfactory bulb. Anat. Sci. Int. 83, 218-227.

Meyer, R. P. (1981). Central connections of the olfactory bulb in the American opossum (Didelphys virginiana): a light microscopic degeneration study. Anat. Rec. 201, 141-156.

Mohedano-Moriano, A., MartinezMarcos, A., Munoz, M., Arroyo-Jimenez, M. M., Marcos, P., Artacho-Perula, E., Blaizot, X., and Insausti, R. (2005). Reciprocal connections between olfactory structures and the cortex of the rostral superior temporal sulcus in the Macaca fascicularis monkey. Eur. J. Neurosci. 22, 2503-2518.

Mohedano-Moriano, A., Pro-Sistiaga, P., Ubeda-Banon, I., Crespo, C., Insausti, R., and Martinez-Marcos, A. (2007). Segregated pathways to the vomeronasal amygdala: differential projections from the anterior and posterior divisions of the accessory olfactory bulb. Eur. J. Neurosci. 25, 2065-2080.

Mohedano-Moriano, A., Pro-Sistiaga, P., Ubeda-Banon, I., de la RosaPrieto, C., Saiz-Sanchez, D., and Martinez-Marcos, A. (2008). V1R and $\mathrm{V} 2 \mathrm{R}$ segregated vomeronasal pathways to the hypothalamus. Neuroreport 19, 1623-1626.

Mouret, A., Murray, K., and Lledo, P. M. (2009). Centrifugal drive onto local inhibitory interneurons of the olfactory bulb. Ann. N.Y. Acad. Sci. 1170, 239-254.

Mucignat-Caretta, C. (2010). The rodent accessory olfactory system. J. Comp. Physiol. A Neuroethol. Sens. Neural Behav. Physiol. 196, 767-777.

Oboti, L., Schellino, R., Giachino, C., Chamero, P., Pyrski, M., LeindersZufall, T., Zufall, F., Fasolo, A., and Peretto, P. (2011). Newborn interneurons in the accessory olfactory bulb promote mate recognition in female mice. Front. Neurosci. 5:113. doi: 10.3389/fnins.2011. 00113

Paxinos, G., and Watson, C. (2007). The Rat Brain in Stereotaxic Coordinates. Amsterdam: Academic Press.

Peele, P., Salazar, I., Mimmack, M., Keverne, E. B., and Brennan, P. A. (2003). Low molecular weight constituents of male mouse urine mediate the pregnancy block effect and convey information about the identity of the mating male. Eur. J. Neurosci. 18, 622-628.

Price, J. L., and Powell, T. P. (1970). An experimental study of the origin and the course of the centrifugal fibres to the olfactory bulb in the rat. J. Anat. 107, 215-237.

Pro-Sistiaga, P., Mohedano-Moriano, A., Ubeda-Banon, I., de la RosaPrieto, C., Saiz-Sanchez, D., and Martinez-Marcos, A. (2008). Projections of olfactory bulbs to the olfactory and vomeronasal cortices. Neuroreport 19, 1541-1544.

Pro-Sistiaga, P., Mohedano-Moriano, A., Ubeda-Banon, I., del Mar Arroyo-Jimenez, M., Marcos, P., Artacho-Perula, E., Crespo, C., Insausti, R., and Martinez-Marcos, A. (2007). Convergence of olfactory and vomeronasal projections in the rat basal telencephalon. J. Comp. Neurol. 504, 346-362.

Raisman, G. (1972). An experimental study of the projection of the amygdala to the accessory olfactory bulb and its relationship to the concept of a dual olfactory system. Exp. Brain Res. 14, 395-408.

Restrepo, D., Arellano, J., Oliva, A. M., Schaefer, M. L., and Lin, W. (2004). Emerging views on the distinct but related roles of the main and accessory olfactory systems in responsiveness to chemosensory signals in mice. Horm. Behav. 46, 247-256.

Rodriguez, I., Feinstein, P., and Mombaerts, P. (1999). Variable patterns of axonal projections of sensory neurons in the mouse vomeronasal system. Cell 97, 199-208.

Ryba, N. J., and Tirindelli, R. (1997). A new multigene family of putative pheromone receptors. Neuron 19, 371-379.

Salazar, I., and Brennan, P. A. (2001). Retrograde labelling of mitral/tufted cells in the mouse accessory olfactory bulb following local injections of the lipophilic tracer DiI into the vomeronasal amygdala. Brain Res. 896, 198-203.

Scalia, F., and Winans, S. S. (1975). The differential projections of the olfactory bulb and accessory olfactory bulb in mammals. J. Comp. Neurol. $161,31-55$.

Scott, J. W., McBride, R. L., and Schneider, S. P. (1980). The organization of projections from the olfactory bulb to the piriform cortex and olfactory tubercle in the rat. J. Comp. Neurol. 194, 519-534.

Shammah-Lagnado, S. J., and Negrao, N. (1981). Efferent connections of the olfactory bulb in the opossum (Didelphis marsupialis aurita): a Fink-Heimer study. J. Comp. Neurol. 201, 51-63.

Shipley, M. T., and Adamek, G. D. (1984). The connections of the mouse olfactory bulb: a study using orthograde and retrograde transport of wheat germ agglutinin conjugated to horseradish peroxidase. Brain Res. Bull. 12, 669-688.

Skeen, L. C., and Hall, W. C. (1977). Efferent projections of the main and the accessory olfactory bulb in the tree shrew (Tupaia glis). J. Comp. Neurol. 172, 1-35.

Spehr, M., Kelliher, K. R., Li, X. H., Boehm, T., Leinders-Zufall, T., and Zufall, F. (2006a). Essential role of the main olfactory system in social recognition of major histocompatibility complex peptide ligands. J. Neurosci. 26, 1961-1970.

Spehr, M., Spehr, J., Ukhanov, K., Kelliher, K. R., Leinders-Zufall, T., and Zufall, F. (2006b). Parallel processing of social signals by the mammalian main and accessory olfactory systems. Cell. Mol. Life Sci. 63, 1476-1484.

Taniguchi, K., and Saito, S. (2011). Phylogenic outline of the olfactory system in vertebrates. J. Vet. Med. Sci. 73, 139-147.

Trinh, K., and Storm, D. R. (2004). Detection of odorants through the main olfactory epithelium and vomeronasal organ of mice. Nutr. Rev. 62, S189-S192. discussion S224-S241.

Turner, B. H., Gupta, K. C., and Mishkin, M. (1978). The locus and cytoarchitecture of the projection areas of the olfactory bulb in Macaca mulatta. J. Comp. Neurol. 177, 381-396.

Ubeda-Banon, I., Novejarque, A., Mohedano-Moriano, A., ProSistiaga, P., de la Rosa-Prieto, C., Insausti, R., Martinez-Garcia, F., Lanuza, E., and Martinez-Marcos, A. (2007). Projections from the posterolateral olfactory amygdala to the ventral striatum: neural basis for reinforcing properties of chemical stimuli. BMC Neurosci. 8, 103.

Ubeda-Banon, I., Novejarque, A., Mohedano-Moriano, A., ProSistiaga, P., Insausti, R., MartinezGarcia, F., Lanuza, E., and MartinezMarcos, A. (2008). Vomeronasal inputs to the rodent ventral striatum. Brain Res. Bull. 75, 467-473.

Ubeda-Banon, I., Pro-Sistiaga, P., Mohedano-Moriano, A., SaizSanchez, D., de la Rosa-Prieto, C., Gutierrez-Castellanos, N., Lanuza, E., Martinez-Garcia, F., and Martinez-Marcos, A. (2011). Cladistic analysis of olfactory and vomeronasal systems. Front. Neuroanat. 5:3. doi: 10.3389/fnana. 2011.00003

Von Campenhausen, H., and Mori, K. (2000). Convergence of segregated pheromonal pathways from the accessory olfactory bulb to the cortex in the mouse. Eur. J. Neurosci. $12,33-46$.

Wang, Z., Balet Sindreu, C., Li, V., Nudelman, A., Chan, G. C., and Storm, D. R. (2006). Pheromone detection in male mice depends on signaling through the type 3 adenylyl cyclase in the main olfactory epithelium. J. Neurosci. 26, 7375-7379.

Whitman, M. C., and Greer, C. A. (2007). Synaptic integration of adult-generated olfactory bulb granule cells: basal axodendritic centrifugal input precedes apical dendrodendritic local circuits. $J$. Neurosci. 27, 9951-9961. 
Winans, S. S., and Scalia, F. (1970). Amygdaloid nucleus: new afferent input from the vomeronasal organ. Science 170, 330-332.

Xu, F., Schaefer, M., Kida, I., Schafer, J., Liu, N., Rothman, D. L., Hyder, F., Restrepo, D., and Shepherd, G. M. (2005). Simultaneous activation of mouse main and accessory olfactory bulbs by odors or pheromones. J. Comp. Neurol. 489, 491-500.

Zaborszky, L., Carlsen, J., Brashear, H. R., and Heimer, L. (1986). Cholinergic and GABAergic afferents to the olfactory bulb in the rat with special emphasis on the projection neurons in the nucleus of the horizontal limb of the diagonal band. J. Comp. Neurol. 243, 488-509.

Zheng, L. M., Ravel, N., and Jourdan, F. (1987). Topography of centrifugal acetylcholinesterase-positive fibres in the olfactory bulb of the rat: evidence for original projections in atypical glomeruli. Neuroscience 23, 1083-1093.

Conflict of Interest Statement: The authors declare that the research was conducted in the absence of any commercial or financial relationships that could be construed as a potential conflict of interest.

Received: 15 April 2012; paper pending published: 02 May 2012; accepted: 12 May 2012; published online: 29 May 2012.

Citation: Mohedano-Moriano A, de la Rosa-Prieto C, Saiz-Sanchez D, UbedaBañon I, Pro-Sistiaga P, de Moya-Pinilla $M$ and Martinez-Marcos A (2012)
Centrifugal telencephalic afferent connections to the main and accessory olfactory bulbs. Front. Neuroanat. 6:19. doi: 10.3389/fnana.2012.00019

Copyright (c) 2012 Mohedano-Moriano, de la Rosa-Prieto, Saiz-Sanchez, UbedaBañon, Pro-Sistiaga, de Moya-Pinilla and Martinez-Marcos. This is an openaccess article distributed under the terms of the Creative Commons Attribution Non Commercial License, which permits non-commercial use, distribution, and reproduction in other forums, provided the original authors and source are credited. 